\title{
Effects of Economic Freedom on Bank Profit Beta-Convergence in ASEAN-5 Banking Sectors
}

\author{
Woon Kan Yap ${ }^{1+}$, Siong Hook $\mathrm{Law}^{2}$, and Judhiana Abdul-Ghani ${ }^{2}$ \\ ${ }^{1}$ Universiti Tun Abdul Razak, Malaysia \\ ${ }^{2}$ Universiti Putra Malaysia, Malaysia
}

\begin{abstract}
This study examines the beta-convergence of bank profitability to the long-run equilibrium, which is the level at which all incumbent banks tend toward when behaving competitively. This study also considers the role of economic freedom in bank profitability convergence, which is a necessary development if banking sectors are to integrate. The results show that ASEAN-5 banking sectors are generally competitive because bank profits and return on average assets are found to beta-converge to their respective competitive levels. Although no evidence exists that the pace of convergence is significantly determined by the prevailing level of economic freedom, freedom in the credit markets and the size of governments are required to satisfy certain thresholds if bank profitability beta-converges significantly.
\end{abstract}

Keywords: credit market freedom, size of government, beta-convergence

JEL Classifications: D2, G21, G28

Received 4 December 2019, Revised 8 June 2020, Accepted 29 June 2020

\section{Introduction}

Following the inauguration of the ASEAN Banking Integration Framework (ABIF), ASEAN members are expected to step up their efforts to liberalize their banking sectors to facilitate a higher level of integration among themselves and with the global banking system. This increased integration is expected to foster the convergence of profitability among ASEAN banks as competition abounds in the banking sectors from domestic banks' exposure to their fellow ASEAN rivals.

From a revenue perspective, stronger rivalry following higher economic freedom through liberalization will cause the demand curve for banking outputs to be more elastic, which then

+Comesponding Author: Woon Kan Yap

Assistant Professor, Tun Abdul Razak School of Government, Universiti Tun Abdul Razak, Jalan Tun Razak, 50400 Kuala Lumpur, Malaysia, Email: anthony@unirazak.edu.my

Co-Author: Siong Hook Law

Faculty of Economics and Management, Universiti Putra Malaysia, Serdang, Seri Kembangan, 43400 Selangor, Malaysia, Email: lawsh@upm.edu.my

Co-Author: Judhiana Abdul-Ghani

Faculty of Economics and Management, Universiti Putra Malaysia, Serdang, Seri Kembangan, 43400 Selangor, Malaysia, Email: judhiana@upm.edu.my 
restrains banks' ability to mark up. Hence, banks are expected to earn only normal long-run profits when banking markets tend toward perfect competition, as argued by the neoclassical school of economics. This situation sets the stage for bank profitability to converge in the long-run. Banks that are not sufficiently competitive and productive will face the consequence of being put out of business by their rivals. Consequently, a high concentration of sufficiently efficient banks is expected to transpire in banking sectors, as predicted by the Efficient Structure (ES) hypothesis from Demsetz (1973). The ES hypothesis suggests that incumbent banks tend to be equally efficient with almost identical cost structures to avoid being displaced through peer rivalry.

Given that the theoretical argument underlying bank profitability convergence relies on the assumption of a liberalized banking market, regulatory exploitations that protect certain domestic players can categorically prevent bank profitability from converging. Liu et al. (2018) found that such protectionist policies confer market power to politically connected firms, which then allows them to earn excess profits that are attributable to unproductive rents. Therefore, allowing freedom in the banking sectors will ensure that incumbent banks are competing on a level playing field.

Hence, this study examines bank profitability convergence in ASEAN-5 banking sectors before ascertaining how economic freedom affects such a convergence. The two aspects of economic freedom that are evaluated in this study are the freedom arising from credit market liberalization and reduced government size. A liberalized credit market is expected to aid in bank profitability convergence on the eradication of undue protectionist initiatives or the political patronage that hinders a level playing field.

Since members of the ASEAN-5 often grow their economies through state expenditures, banks are resultantly motivated to expand their loan portfolios, supported by higher asset prices. Moreover, state-connected banks are more likely to be involved in public projects that are initiated by the state relative to banks that are not state-connected. Hence, profits of these state-connected banks are generally persistent. Because incessant state spending is unsustainable, the anticipated scaling back of the government's size is expected to reinvigorate the rivalry among banks to drive their profitability to a common level. Hence, a higher degree of economic freedom resulting from a smaller-sized government is foreseen to aid with convergence.

Whereas the correlation between economic freedom and bank profitability is theoretically rigorous, it is not empirically robust. Although most empirical studies observed the said correlation, studies such as Gugler and Peev (2018), Goddard et al. (2011), and Chronopoulos et al. (2015) found contrary results. In fact, Chronopoulos et al. (2015) suggested that deregulation may create opportunities for big players to diversify their activities to enable them to grow into universal banks and have market power conferred on them. Therefore, pertinent to this study is to ascertain the route that ASEAN-5 banks take when more freedom is accorded to them- 
whether they resultantly become more competitive and efficient or embark on non-productive activities, such as colluding among themselves to erect high entry barriers.

This study is expected to contribute to the literature in numerous ways. First, the findings from this study constitute important knowledge that will guide policymakers throughout their course of liberalizing economies to enable greater banking integration. Particularly, this study is expected to assist policymakers in sequencing optimal economic reforms, given that all economic freedoms do not have identical and consistent effects on banking sectors.

Second, this study sheds light on the mobility of banking resources and their efficient use by examining bank profitability convergence and the factors that affect this convergence. Bank profitability convergence - driven by competition - bears significance because it constitutes a necessary condition for resources to be allocated efficiently for financial sector development. If the resource allocation is fully unhindered, then resources are first invested in the bank that provides the highest returns. Once the law of diminishing marginal returns sets in, subsequent resource units are allocated to the next best alternative, and so on, until the returns of all banks equalize. In this way, banking resources are put to the best use possible.

Estimations of the beta-convergence model proposed by Barro and Sala-i-Martin (1992) using the Generalized Method of Moment (GMM) estimator (Arellano and Bover, 1995) reveal that ASEAN-5 banks' profitability significantly beta-converge. However, higher freedom-whether from credit market liberalization or a reduction in the government's size-is not found to have any significant marginal effect on bank profitability convergence. Even so, the conditional relationships among these freedom variables on the beta-convergence of bank profitability still exist because the coefficients of beta-convergence only become significantly beyond a certain minimum score on each freedom index.

This study comprises six sections. The second section presents a review of the extant empirical literature, whereas the third section expounds on the theoretical framework of convergence before presenting the adopted methodology in the fourth section. The fifth section discusses the results of the analysis of this study. Lastly, the final section presents a conclusion.

\section{Review of Empirical Literature}

The extant literature on the dynamics of bank profitability focuses extensively on its persistence rather than convergence. Nonetheless, both sets of studies are interrelated because the former is theoretically regarded as the antitheses of the latter. The bank profits that persist higher than the normal level are often theorized to be sustained by market power, given the absence of competition. Hence, studies that corroborate high persistency (non-convergence) in bank profitability constitute evidence against the prediction made by the neoclassical school, 
which suggests that banks should earn normal profits in the long-run as the banking market becomes perfectly competitive. The reverse is true for studies that uncovered low persistence in bank profitability.

By using a dynamic panel estimator to examine the determinants of bank profitability, Athanasoglou et al. (2008), García-Herrero et al. (2009), and Sinha and Sharma (2016) observed that the first-order lag of the bank profitability variable plays a significant role - but of a moderate magnitude - in determining the current profitability. Thus, they concluded that bank profits are reasonably persistent in the Greek, Chinese, and Indian banking sectors.1) In contrast, Garza-Garcia (2012) found that the persistence rate of bank profits in Mexico was exorbitantly high, at 0.82, implying an uncompetitive banking sector because of restricted contestability.

Paradoxically, although the United States has the freest economy in the world, Chronopolous et al. (2015) uncovered that the persistence rate of bank profits for the U.S. banking sector was arguably high, at 0.62 , which was higher than the persistence rate of the Chinese banking sector at 0.4 (García-Herrero et al., 2009). In contrast, by applying the time series method to the Turkish banking sector, Bektas (2007) found that the long-run profit series of Turkish banks from 1989 to 2003 turned out to be stationary. Hence, unlike most other studies, he uncovered no evidence to suggest that Turkish banks' profits are persistent over the long-run.

In addition to ascertaining the persistence of bank profitability, some extant studies also undertook to uncover significant factors or variables that explain such persistence. Among these variables are ownership concentration (Agostino et al., 2005), the extent and types of regulation (Amidu and Harvey, 2016; Chronopolous et al. 2015), loan loss provision (Amidu and Harvey, 2016, financial crisis (Chronopolous et al. 2015), market entry restrictions, market concentration, the prevailing level of competition (Goddard et al., 2011), and bank capitalization (Gugler \& Peev, 2018). Intriguingly, Pervan et al. (2015) found that the persistence of bank profitability is not necessarily determined by exogenous factors but by the level of bank profitability itself. Banks that are saddled with low profitability are observed to have a higher degree of persistence, and the opposite is true for banks with high profitability.

Although the literature is suffused with studies that examined the persistence of bank profitability, only a handful analyzed convergence. These studies ${ }^{2}$ include Evans et al. (2008), Goddard et al. (2013), and Olson and Zoubi (2017). Both Evans et al. (2008) and Goddard et al. (2013) explained that the uncovered convergence of bank profits among European banks was the result of economic integration. These studies affirmed that opening up the national borders to facilitate deeper integration of the EU financial markets promotes the convergence

1) Specifically, the measured persistence rate is $0.35,0.4$ (average across different approaches), and 0.4 for the Greek, Chinese, and Indian banking sectors, respectively.

2) In passing, a large number of studies examined the convergence of bank efficiency rather than bank profitability. These studies include Kasman and Kasman (2013), Casu and Girardone (2010), Weill (2009), and Mamatzakis et al. (2008), among others. 
of bank profits as competition abounds. However, when different profitability indexes are examined for their convergence, the results are incoherent. Although bank profitability indexes, such as return on assets and return on equity, are predisposed to converge, Evans et al. (2008) did not observe any convergence in the asset-liability practices that banks adopted.

Apart from that, financial crises are suggested to foster bank profit convergence, given that Olson and Zoubi (2017) found evidence of stronger convergence in bank profitability across multiple regions after the global financial crisis. They used the log t-test, as proposed by Phillips and Sul (2007). This result is expected because banking sectors often go through consolidation and concentration after periods of crises, whether because of the regular liquidation of weaker banks or the authorities' concerted effort to strengthen the banking sectors.

To conclude, most of the extant studies that examined the persistence of bank profitability reached a consensus that bank profits generally persist at least in the short term. However, the magnitude and nature of the persistence vary across studies and countries. In contrast, the studies that examined convergence generally found that regionalization promotes bank profitability convergence (Evans et al., 2008; Goddard et al., 2013). Although the same integration-convergence hypothesis can be applied to the ASEAN region, the empirical literature to date has provided no explanation for how economic freedom variables affect bank profitability convergence, which is the topic to be addressed by this study.

\section{A. Economic freedom and regionalization}

The 53-year-old ASEAN was first founded with only the intention to foster a higher level of cooperation in the economic, social, cultural, technical, educational, and other fields among the initial five members: Malaysia, Singapore, Thailand, Indonesia, and the Philippines (collectively known as the ASEAN-5). However, over the years, with the addition of another five members, the call for deeper integration has become more resounding with the inauguration in 1997 of the ASEAN Vision 2020. This vision aims to establish an economically integrated and culturally identical region by 2020, as spelled out in greater detail in the ASEAN Economic Community blueprint implemented in 2007.

However, ASEAN Vision 2020 does not include explicit recommendations about the need for democratization to underpin market sovereignty because the strategic preference for state sovereignty and domestic regime security are too deeply entrenched in the ASEAN member states. This situation has undermined the imperatives of market sovereignty and, thus, has worked against the complete integration of the ASEAN economies (Kim, 2011). As a result, Jones and Smith (2007) argued that all of the declarations and goals for an integrated ASEAN economy are merely rhetorical as the member states prioritize their national interests, which are frequently anchored in the security of their domestic regimes over supranational community 
building.

In addition, Jones (2016) suggested that the state-led development in Southeast Asian economies has created a symbiotic state-business relationship that has prevented a more holistic and comprehensive economic liberalization as public policymaking is swayed by business interests. Although the sectors that can compete internationally do not abhor liberalization, others that have weaker performance use their influence to foil it. More frequently than not, sectors with a weaker performance are usually state-linked.

Although reigning in the state's influence in the economy is necessary to allow for meaningful regional integration, the recent military rule in Myanmar and Thailand, the history of long periods of dictatorship in the Philippines and Indonesia, the authoritarian governments in Laos, Cambodia, and Vietnam, the monarchical state of Brunei, and the one-party system of Singapore all suggest that the ASEAN economies are heavily state-dominated. Market sovereignty remains evasive because these countries have an organic and structural politico-economic connection that thwarts every effort to integrate these economies.

\section{Theoretical Framework of Convergence}

The notion of convergence employed in this study is notably proprietary to the Solow-Swan growth model. This notion generally asserts that all countries eventually grow at an identical constant rate because of the law of diminishing marginal productivity of capital (Barro \& Sala-i Martin, 1992). The convergence of firms' profits, similar to that applied in microeconomics, is a realization of the neoclassicists' prediction of the normal profits associated with long-run market equilibrium. In a highly contestable market, incumbent firms' profits are expected to converge to the normal or competitive level in the long-run. Therefore, by examining the convergence or persistence of profitability, the efficacy of competition in normalizing firms' performances can be discerned (Mueller, 1977). Firms' profitability that is persistently higher than the norm indicates that the prevailing forces of competition are allegedly weak.

When firms' profitability is measured as the return on average assets (ROAA), then the basis for convergence is also underpinned by the law of diminishing marginal returns. By assuming that the movement of banking resources is unimpeded and such resources are always on the lookout for assets with a higher return to invest in, then the ROAA is expected to equalize if the law of diminishing marginal returns applies.

However, convergence does not necessarily occur in absolute terms. Therefore, the convergence model must control for any discrepancies in the structural or long-run parameters. In other words, when beta-convergence takes place, banks' profitability is expected to tend toward a common steady-state that is proxied by these long-run parameters. Hence, this is subsequently 
known as the conditional beta-convergence model (Sala-i Martin, 2002).

\section{Methodology: Model, Specification of Variables, and Estimation}

For the purpose of robustness, two bank profitability measures — bank profits and ROAA — are examined in this study for their tendencies to converge through an estimation of the growth model.

\section{A. Model specification}

First, the fundamental growth model in this study that estimates the convergence of bank profits is as follows:

$$
\begin{aligned}
\triangle \ln P B T_{i, t}= & \alpha_{0}++\beta_{1} \ln P B T_{i, t-1}+\sum_{\tau=1}^{2} \beta_{2, \tau}\left(l n P B T_{i, t-1} * E F_{t, \tau}\right)+\beta_{3, \tau}\left(E F_{t, \tau=1} * E F_{t, \tau=2}\right) \\
& +\beta_{4} \triangle \ln P B T_{i, t-1}++\sum_{\tau=1}^{2} \beta_{5, \tau} E F_{t, \tau}+\sum_{m=1}^{3} \delta_{m} x_{m, i, t}+\varepsilon_{i, t}
\end{aligned}
$$

where the dependent variable $\triangle \ln P B T_{i, t}$ is given as $\triangle \ln P B T_{i, t}-\triangle \ln P B T_{i, t-1}$, whereas $\triangle \ln P B T_{i, t}$ and $\triangle \ln P B T_{i, t-1}$ represent the non-negative profits before taxes $(P B T)$ in the logarithm for the $i$ th bank during period $t$ and period $t-1$, respectively. $\varepsilon_{i, t}$ is an error term that is not expected to be spherical if an appropriate estimator is not used to estimate Eq (1) (further discussion on the non-sphericity of the error term is provided in subsection 4.3). $E F_{t, \tau}$ refers to the economic freedom variables that include the credit market regulation index $\left(C M R I_{t}\right)$ and the size of the government $\left(S O G_{t}\right)$, which measure the prevalence of freedom arising from a more liberalized credit market and a smaller government, respectively. Given the low correlation between the economic freedom variables, they are simultaneously entered into the model to ascertain their conditioning effects on bank profitability convergence. The subscript $\tau$ denotes the estimated coefficients for the respective economic freedom variable: $\tau=1$ and $\tau=2$ if $E F_{t, \tau}=C M R I_{t}$ and $E F_{t, \tau}=S O G_{t}$, correspondingly.

In addition to forming the interaction terms, each of the economic freedom variables-as constitutive terms - is also entered into Eq (1) as a regressor (Brambor et al., 2006). Following Aiken and West (1991), $E F_{t, \tau=1} * E F_{t, \tau=2}$ is a multiplicative term that is added to the model to account for the joint distribution of the conditioning variables, which are the economic freedom variables. Because each of the economic freedom variables is expected to covary with the lagged dependent variable, expecting them to covary with each other is intuitive.

Given that the ASEAN-5 members are structurally polarised, it is highly unlikely that they share common long-run parameters. Therefore, a vector of control variables that are bank- and country-specific represented by $x_{m, i t}$ is included in the convergence model of Eq (1) as proxies 
to the steady-state (see Sala-i-Martin, 2002). The bank-specific control variables comprise of variables that represent the size and risk profiles of the individual banks to condition out any variability in profit growth resulting from structural and risk differentials across banks. In addition, the country-specific control variables are included to hold the macroeconomic performance constant when estimating theconvergence rates. Subsection 4.2 describes in detail the selection of the control variables.

Because bank profits are expressed in logarithmic form, they must be non-negative. Instead of the typical practice of scaling up an individual bank's observed profits before taxes $(P B T)$ using the sample's largest negative value, non-negative profits before taxes $(P B T)$ are obtained by using the inverse hyperbolic sine (IHS) transformation as proposed by Johnson (1949). The HIS transformation was first used in econometrics by Burbidge et al. (1988) as the log transformation for the dependent variable. The logarithm of IHS-transformed non-negative profits before taxes is as follows:

$$
\ln P B T_{i, t}=\ln \left[P B T_{i, t}+\left(P B T_{i, t}^{2}+1\right)^{(1 / 2)}\right]
$$

To avoid serial correlation in the model, $\triangle \ln P B T_{i t-1}$ is included in the beta-convergence model of Eq (1) to account for short term dynamics. In turn, when the convergence of the

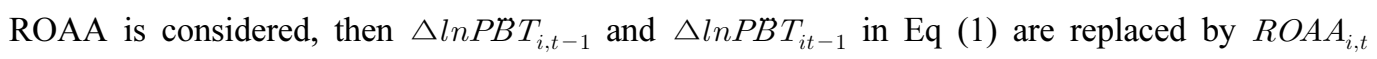
and $R O A A_{i, t-1}$, respectively. ROAA constitutes the net income of a bank normalized by its average assets and is computed by dividing a bank's net profits before taxes with its average assets. Hence, ROAA measures the amount of net income that can be generated for every unit of assets held by a bank.

$\mathrm{Eq}$ (1) is re-arranged as follows to unravel the beta-convergence rates and the conditioning effects of economic freedoms on bank profitability convergence:

$$
\begin{aligned}
\triangle \ln P B T_{i, t}= & \alpha_{0}+\left(\beta_{1}+\sum_{\tau=1}^{2} \beta_{2, \tau} E F_{t, \tau}\right) \ln P B T_{i, t-1}+\beta_{3, \tau}\left(E F_{t, \tau=1} * E F_{t, \tau=2}\right) \\
& +\beta_{4} \triangle \ln P B T_{i, t-1}+\sum_{\tau=1}^{2} \beta_{5, \tau} E F_{t, \tau}+\sum_{m=1}^{3} \delta_{m, \tau} x_{m, i, t}+\varepsilon_{\tau, i, t}
\end{aligned}
$$

The overall beta-convergence rate, $\widetilde{\beta}_{1}$, as the coefficient associated with $\ln P B T_{i, t-1}$, is then recovered as follows:

$$
\widetilde{\beta}_{1}=\beta_{1}+\beta_{2, \tau=1} E F_{t, \tau=1}+\beta_{2, \tau=2} E F_{t, \tau=2}
$$

To examine the significance of the convergence coefficient, $\widetilde{\beta_{1}}$, its standard error $\left(\sigma_{\widetilde{\beta_{1}}}\right)$ is computed as follows, which is based on Aiken and West (1991): 


$$
\begin{aligned}
& \sigma_{\widetilde{\beta_{1}}}=\left\{\operatorname{var}\left(\beta_{1}\right)+\operatorname{var}\left(\beta_{2, \tau=1}\right) * E F_{t, \tau=1}^{2}+\operatorname{var}\left(\beta_{2, \tau=2}\right) * E F_{t, \tau=2}^{2}+2 * \operatorname{cov}\left(\beta_{1}, \beta_{2, \tau=1}\right) * E F_{t, \tau=1}\right. \\
&\left.+2 * \operatorname{cov}\left(\beta_{1}, \beta_{2, \tau=2}\right) * E F_{t, \tau=2}+2 * \operatorname{cov}\left(\beta_{2, \tau=1}, \beta_{2, \tau=2}\right) * E F_{t, \tau=1} * E F_{t, \tau=2}\right\}^{1 / 2}
\end{aligned}
$$

where var and cov denote the variance and covariance, respectively.

Theoretically, the beta-convergence rate $\left(\widetilde{\beta}_{1}\right)$ should take a value less than zero and a larger absolute value indicates a higher propensity for bank profitability to converge, which is synonymous to a faster speed of convergence that is computed as follows:

$$
\text { speed of convergence }=\frac{1}{\left|\widetilde{\beta_{1}}\right|}
$$

In contrast, if $\widetilde{\beta}_{1} \geq 0$, then the bank profitability series is deemed persistent because it systematically deviates from the competitive level without any prospective corrections. If economic freedom contributes to bank profitability convergence, then the coefficients $\beta_{2, \tau=1}$ and $\beta_{2, \tau=2}$ should be significantly less than zero.

\section{B. Specification of variables}

The two economic freedom variables included in this study - the credit market regulation index $(C M R I)$ and the size of the government $(S O G)$ — which respectively track the extent of freedom in credit markets and the state's interference in the economy through its fiscal position, are both obtained from the Fraser Institute's Economic Freedom of the World Index. Notably, the underlying components that comprise the CMRI index are interest rate control, state ownership of banks, and the extent of credit allocated to the private sector. The components that comprise the $S O G$ index include transfers and subsidies, government consumption, and marginal tax rates.

As previously mentioned, certain proxies are necessarily entered into the beta-convergence model specified in Eq (1) to determine the long-run competitive level. If the coefficients $\left(\delta_{m, \tau}\right)$ in Eq (1) differ significantly from zero, then bank profits are said to only beta-converge to a competitive level when holding these proxies constant. Hence, these selected proxies are needed to explain the discrepancies among the incumbent banks that cause their performances to vary. Notably, these discrepancies are typically explained by the differences in certain structural $^{3)}$ attributes, such as bank size and risk preference.

Underpinned by the concept of economies of scale, bank profitability, especially if it is measured as profit before tax, is known to persist at the level determined by the size of individual

3) In this context, structural refers to items in banks' balance sheets. 
banks. This statement is corroborated by Akhigbe and McNulty (2005), who found that larger banks tend to be significantly more profit-efficient than smaller banks. Therefore, controlling for the scale effects is pertinent. This study, which is similar to many others, measures bank size as the logarithm of banks' total assets ( $L N T A)$. Intuitively, the estimated coefficient of $L N T A$ should assume a positive value because banks with larger assets are expected to be more profitable if scale efficiency prevails.

Besides, individual banks' risk appetite also contributes to the persistence of their profitability, following the principle of risk-return trade-off. Theoretically, banks that have riskier assets tend to seek higher returns as compensation by pricing for risk. Thus, banks with riskier portfolios have a persistently higher expected profitability than that of risk-averse banks. Incidentally, in this study, the measure of a bank's risk preference focuses on the exposure to asset risk, which is given as the quotient of loan loss reserves and total loans (LLRTL).

Since African banks are revealed by Amidu and Harvey (2016) to be less profit persistent when the Global Financial Crisis (GFC) took place, it implies that disturbances attributable to macroeconomic conditions have a certain bearing on the convergence of bank profitability. Conjecturally, a financial crisis could have acted as an agent that redistributes profits from large but inefficient banks to small but efficient banks. In other words, financial crises could be game-changers. Thus, this study accounts for the effects of macroeconomic conditions by controlling for the GDP growth rate $(R G D P)$.

\section{Consistent estimator}

The model is estimated by applying generalized method of moments (GMM) type of estimators to account for the lagged dependent variable in Eq (1) as an endogenous regressor. However, because the persistence of bank profitability is not expected to be low on the basis of the extant literature that analyzes the dynamics of bank profitability, the standard GMM estimator - known as the first-difference GMM - as originally proposed by Arellano and Bond (1991) is no longer appropriate.

Indeed, the presence of a near unit root in a time series is expected to exacerbate the finite-sample bias. Therefore, this study instead employs the system-GMM proposed by Arellano and Bover (1995), which comprises a system of equations that includes the first-difference equations that are instrumented by lagged levels, as suggested by the first-difference GMM estimator in Arellano and Bond (1991), and the level equations that are instrumented by a set of lagged first-difference instruments.

The two-step GMM estimation technique is employed in this study to ensure that the estimation is robust to any form of heteroskedasticity. Although the standard errors of the two-step GMM estimation are asymptotically efficient, they are biased, especially in a small 
sample (Roodman, 2009a). Hence, this study adjusts the standard errors of the two-step estimates using the correction proposed by Windmeijer (2005).

Apart from that, Roodman (2009b) contended that an explosive number of instruments weakens the Hansen $J$ test for overidentifying restrictions. Therefore, this study reduces the dimensionality of the instrumental variables' matrix by making the number of instruments linear, instead of quadratic, in $t$. This linearity is achieved by using the method proposed by Calderón et al. (2002), which collapses the matrix horizontally.

Moreover, Roodman (2009a) advocated the use of the forward orthogonal deviation (FOD) transformation, as proposed by Arellano and Bover (1995), to remove the fixed effects, instead of first differencing the model. The FOD transformation has an advantage over first differencing, given that the latter is known to magnify the effects of loss of data in an unbalanced panel. Whereas first differencing involves subtracting the first lag of a variable from its contemporaneous observation to remove the fixed effects, the FOD transformation instead subtracts the average of all future observations from its contemporaneous observation. Therefore, except for the first observation, the FOD transformation is computable for every other observation regardless of the number of gaps. In addition, Hayakawa (2009) used a Monte Carlo simulation to conclude that the FOD transformation works better than first differencing. Consequently, in this study, the FOD transformation is also estimated as a robustness check.

\section{Sample and data}

This study consists of a sample comprised of an unbalanced panel of 135 banks that operated in the ASEAN-5 member states from 2010 until 20154) (six years). To yield a representative sample, only commercial banks with at least three years of data are selected. After filtering, our sample comprises 764 bank-year observations, as summarized in Table 1.

Table 1. Distribution of Observations

\begin{tabular}{ccccccc}
\hline ASEAN-5 Member & 2010 & 2011 & 2012 & 2013 & 2014 & 2015 \\
\hline INDONESIA & 52 & 65 & 66 & 66 & 68 & 68 \\
MALAYSIA & 5 & 21 & 21 & 22 & 22 & 22 \\
PHILIPPINES & 17 & 19 & 20 & 20 & 20 & 20 \\
SINGAPORE & 7 & 7 & 7 & 7 & 7 & 7 \\
THAILAND & 17 & 18 & 17 & 18 & 18 & 18 \\
Total & 98 & 130 & 131 & 135 & 135 & 135 \\
\hline
\end{tabular}

(Note) A comprehensive summary of the descriptive statistics that reveal the attributes of the dataset is provided in Appendix A.

4) The Fraser Institute updates the Economic Freedom of the World Index annually, but the most recent record at the time of this writing is 2016. In addition, data on other earning assets variable are sparse for years before 2010 on the basis of the FitchConnect database. Thus, the sample period starts in 2010 . 


\section{Results of Analysis and Discussion}

The proliferation of the interaction terms that involve the lag of bank profitability variables $\left(\ln P B T_{i, t-1}\right.$ or $\left.R O A A_{i, t-1}\right)$ in Eq (1) caused a number of the regressors to be highly correlated, as shown in the Pearson correlation matrix in Appendix B(i). The pairs of highly correlated regressors can be categorized into two groups. The first group involves the lags of the bank profitability variables and their respective interaction terms with the economic freedom variables (correlation coefficients in italics in Appendix B(i)).

Multicollinearity that involves multiplicative interaction terms is deemed a non-issue, as referenced by Brambor et al. (2006) and Friedrich (1982). Whereas the coefficients in a linearadditive model indicate the average effects of the associated variables, the coefficients of multiplicative interaction variables do not have the same meaning. For example, if the two regressors $X_{1}$ and $X_{2}$ are highly collinear, then the estimated effects of $X_{1}$ on the dependent variable when holding $X_{2}$ constant is highly inaccurate because $X_{2}$ cannot remain constant when $\mathrm{X}_{1}$ varies, given the high collinearity between them. However, considering two regressors, of which one is an interacted term of another $-X_{1} * X_{2}$ and $X_{2}$ - then the coefficients associated with each of these regressors should not be interpreted as the average effects, holding the other term constant. In fact, the two regressors are expected to covary. Therefore, the resultant high variance of the coefficient associated with $\mathrm{X}_{2}$ when an interaction term is included should not be taken as the effect of multicollinearity per se.

The second group of highly correlated pairs of variables refers to the bank size (LNTA) variable and the first lag of the non-negative profits before taxes at level $\left(\ln P B T_{i, t-1}\right)$ as well as its associated interaction terms (correlation coefficients in italics and underlined in Appendix $\mathrm{B}(\mathrm{i})$ ). Although these correlation coefficients exceed the threshold of 0.8 , as suggested by Kennedy (2008), dropping LNTA from the model is not possible. As expounded in subsection $4.2, L N T A$ is a necessary proxy to condition out the disparities in bank profits to allow for beta-convergence.

Although the implications of multicollinearity are known to render the estimates inefficient (high variance), ascertaining how inefficient they are is not possible unless the variance inflation factor (VIF) is calculated. Therefore, the VIFs for these highly correlated terms are computed in Appendix B(ii) by regressing Eq (1) ${ }^{5}$ three times and each time including only one term that involves the lagged non-negative profits before taxes, $\left.{ }^{6}\right)$ that is, $\ln P B T_{i, t-1}(\mathrm{M} 1), \ln P B T_{i, t-1} * C M R I_{t}$ (M2) and $\ln P B T_{i, t-1} * S O G_{t}(\mathrm{M} 3)$.

5) The dummies for country income are not accounted for in the regressions that estimate the VIF.

6) The terms involving the lagged level of non-negative profits before taxes are regressed individually because the purpose of this study is to examine the degree to which the variance has been inflated from their high collinearity with $L N T A$ and not from the high collinearity among them. 
Because Hair et al. (1995) set the VIF threshold at 10, which is much higher than any of the VIFs shown in Appendix B(ii), further remedial actions are not pursued despite the high correlation between $L N T A$ and other terms involving the lagged non-negative profits before taxes, given that the inflated variance is still tolerable.

\section{A. Beta-convergence of bank profits}

Table 2 presents the estimates of the bank profits convergence model as per Eq (1). Two alternate approaches are employed to ensure that the estimation is robust. Their respective estimates are then compared. Although both approaches use system-GMM, the first approach in column 2.1a of Table 2 removes the fixed effects through first differencing, and the second approach in column $2.1 \mathrm{~b}$ uses the forward orthogonality method as discussed in section 4.3 .

Table 2 shows that none of the coefficient associated with the lagged dependent variable, $\beta_{1, \pi}$, and the economic freedom interaction terms, $\beta_{2, \pi, \tau=1}$ and $\beta_{2, \pi, \tau=2}$, are found to be significant regardless of whether the first differencing or the forward orthogonality approach is adopted. Therefore, both approaches are consistent in yielding no significant evidence that suggests a faster rate of bank profit convergence following increased economic freedom in the ASEAN-5 members.

Despite the insignificance of the interaction terms, Brambor et al. (2006) suggested that the conditional relationship still prevails if the parameter of interest becomes significant when the conditioning variable satisfies a certain threshold. As a result, the insignificance of the interaction terms does not necessarily nullify the hypothesized conditional relationship. Indeed, Figure 1 plots the beta-convergence rates over a range of CMRI scores on the basis of Eq (4) while holding the SOG score constant at its mean, ${ }^{7)}$ showing that the convergence rate becomes significant at the $10 \%$ level when the CMRI score is at least 7.8 ) Hence, the conditional relationship between the CMRI index and the convergence of bank profits still prevails in the ASEAN-5 banking sectors, although the marginal effect of the former on the latter is found to be insignificant.

In addition, in Figure 1, the noted convergence of bank profits from conditioning out banks' structural disparities and macroeconomic conditions constitutes a refutation of the argument in Mueller (1983), which suggests that only the profit rates or ratios are expected to equalize in the long-run but not the profits. Instead, the convergence of bank profits among the ASEAN-5 banks indicates that market forces efficiently allocate banking assets. Therefore, ASEAN-5 banks' profits are expected to tend toward a competitive level, which is consistent with the

7) Because Eq (4) constitutes a double interaction term model, holding one conditioning variable constant is necessary when examining the conditional relationship of another.

8) Only when the CMRI index score is at least 7 are both the upper and lower bounds of the $90 \%$ confidence interval are less than zero. 
Table 2. Convergence of Bank Profits Conditioned by the Effects of Economic Freedom

\begin{tabular}{|c|c|c|c|c|}
\hline & \multicolumn{4}{|c|}{ Convergence of bank profits } \\
\hline & \multicolumn{2}{|c|}{$\begin{array}{l}\text { Model 2.1a: } \\
\text { First differencing }\end{array}$} & \multicolumn{2}{|c|}{$\begin{array}{l}\text { Model 2.1b: Forward } \\
\text { orthogonality }\end{array}$} \\
\hline & Coef. & $\begin{array}{l}\text { C. Std. } \\
\text { Err. }\end{array}$ & Coef. & $\begin{array}{l}\text { C. Std. } \\
\text { Err. }\end{array}$ \\
\hline \multicolumn{5}{|l|}{ Dependent variable: Non-negative profits before taxes growth rate $\left(\triangle \ln P B T_{i, t-1}\right)$} \\
\hline Lagged level non-negative profits before taxes $\left(\triangle \ln P B T_{i, t-1}\right), \beta_{1, \pi}$ & 0.36 & 1.11 & 0.31 & 1.03 \\
\hline $\begin{array}{l}\text { Lagged level non-negative profits before taxes } * \text { Credit market regulation index } \\
\left(\triangle \ln P B T_{i, t-1} * C M R I\right), \beta_{2, \pi, \tau=1}\end{array}$ & -0.02 & 0.09 & -0.04 & 0.10 \\
\hline $\begin{array}{l}\text { Lagged level non-negative profits before taxes } * \text { size of government } \\
\left(\triangle \ln P B T_{i, t-1} * S O G\right), \beta_{2, \pi, \tau=2}\end{array}$ & -0.09 & 0.11 & -0.06 & 0.09 \\
\hline Credit Market Regulation Index $*$ size of government $(C M R I * S O G), \beta_{3, \pi}$ & -0.24 & 0.39 & -0.20 & 0.34 \\
\hline Lagged difference non-negative profits before taxes $\left(\triangle \ln P B T_{i, t-1}\right), \beta_{4, \pi}$ & 0.04 & 0.11 & 0.03 & 0.09 \\
\hline \multicolumn{5}{|l|}{ Control variables } \\
\hline Logarithm of total assets $(L N T A), \delta_{1, \pi}$ & $0.51^{* *}$ & 0.24 & $0.51^{* * *}$ & 0.20 \\
\hline Loan loss reserve to total loans $(L L R T L), \delta_{2, \pi}$ & -0.07 & 0.09 & -0.07 & 0.08 \\
\hline GDP growth rate $(R G D P), \delta_{3, \pi}$ & $-0.06^{*}$ & 0.03 & $-0.05^{*}$ & 0.03 \\
\hline Credit market regulation index, $\beta_{5, \pi, \tau=1}$ & 1.98 & 3.09 & 1.70 & 2.81 \\
\hline Size of government, $\beta_{5, \pi, \tau=2}$ & 2.83 & 4.00 & 2.25 & 3.38 \\
\hline \multicolumn{5}{|l|}{ Year effects } \\
\hline 2012 & $0.42^{* * *}$ & 0.10 & $0.41^{* * *}$ & 0.09 \\
\hline 2013 & $0.26^{* * *}$ & 0.11 & $0.26^{* * *}$ & 0.10 \\
\hline cons, $\alpha_{1}$ & -24.40 & 31.82 & -20.68 & 27.74 \\
\hline No. of Observations & \multicolumn{2}{|c|}{492} & \multicolumn{2}{|c|}{492} \\
\hline No. of Groups & \multicolumn{2}{|c|}{133} & \multicolumn{2}{|c|}{133} \\
\hline No. of Instruments & \multicolumn{2}{|c|}{49} & \multicolumn{2}{|c|}{49} \\
\hline $\mathrm{AB}(1) \mathrm{p}$-value & \multicolumn{2}{|c|}{0.069} & \multicolumn{2}{|c|}{0.070} \\
\hline $\mathrm{AB}(2) \mathrm{p}$-value & \multicolumn{2}{|c|}{0.485} & \multicolumn{2}{|c|}{0.378} \\
\hline (i) Hansen $J$ test p-value & \multicolumn{2}{|c|}{0.398} & \multicolumn{2}{|c|}{0.319} \\
\hline \multicolumn{5}{|l|}{ Difference in Hansen test (p-value) } \\
\hline \multicolumn{5}{|l|}{ GMM instruments for level: } \\
\hline Excluding group & \multicolumn{2}{|c|}{0.654} & \multicolumn{2}{|c|}{0.509} \\
\hline (ii) Lagged first-difference instruments & \multicolumn{2}{|c|}{0.135} & \multicolumn{2}{|c|}{0.162} \\
\hline
\end{tabular}

(Notes) These results are estimated using the two-step system GMM estimator. The corrected standard error (C. Std Err.) presented is as per Windmeijer (2005). Year effects are dutifully examined for each model, and only significant effects for any particular year are accounted for in the model. *, **, and *** indicate the significance of the coefficient (coeff.) at the 10\%,5\%, and 1\% levels, respectively. The coefficient indicators $\pi$ and roaa indicate whether the coefficients are associated with bank profits or the ROAA convergence models. $\mathrm{AB}(1)$ and $\mathrm{AB}(2)$ refer to the Arellano-Bond tests for first- and second-order serial correlations, respectively. (i)-(ii) are the p-values of a series of Hansen $J$ and $C$ tests on the validity of the instruments. (i) refers to the p-value of the overall test on the validity of the instruments. (ii) is the validity tests for the first-difference instruments for the level equations. The dimensionality of the instrumental variable matrix is reduced using the approach proposed by Calderon et al. (2002). 
neoclassical school's prediction, even though this level is determined by banks' structural parameters.

Although freer credit markets are theoretically expected to foster the convergence of bank profits by annihilating the market power accrued to banks, the analysis carried out in this study has uncovered that the extent of the market forces invigorated through a higher level of credit market freedom does not correspondingly increase the convergence rate of bank profits in a significant manner. Nonetheless, the ASEAN-5 members are still required to maintain a minimum level of freedom in their credit markets for bank profits to beta-converge significantly. If the credit market freedom declines to the extent of yielding only a CMRI score lower than 7 , ceteris paribus, the beta-convergence rate of bank profits is expected to become insignificant. Thus, despite the insignificance of the marginal effect of credit market freedom on the convergence of bank profits, governments of the ASEAN-5 countries should still refrain from excessive intervention in their credit markets to avoid breaching the minimum CMRI threshold.

Although the risk is small of an immense $20 \%$ decline from the prevailing average score of 8.83 to the minimum score of 7 , this risk is heightened for Indonesia because it has consistently scored the lowest on the CMRI index, with an average score of 8.07 throughout the observation period. For comparison purposes, other countries that scored lower than 7 on the CMRI index as of 2015 were those with emerging economies, such as Brazil and Argentina.

Figure 1. Beta-convergence rates as determined by the CMRI index on holding the SOG index constant at 7.61 . The estimated parameters of model $2.1 \mathrm{~b}$ are used to plot the beta-convergence rates.

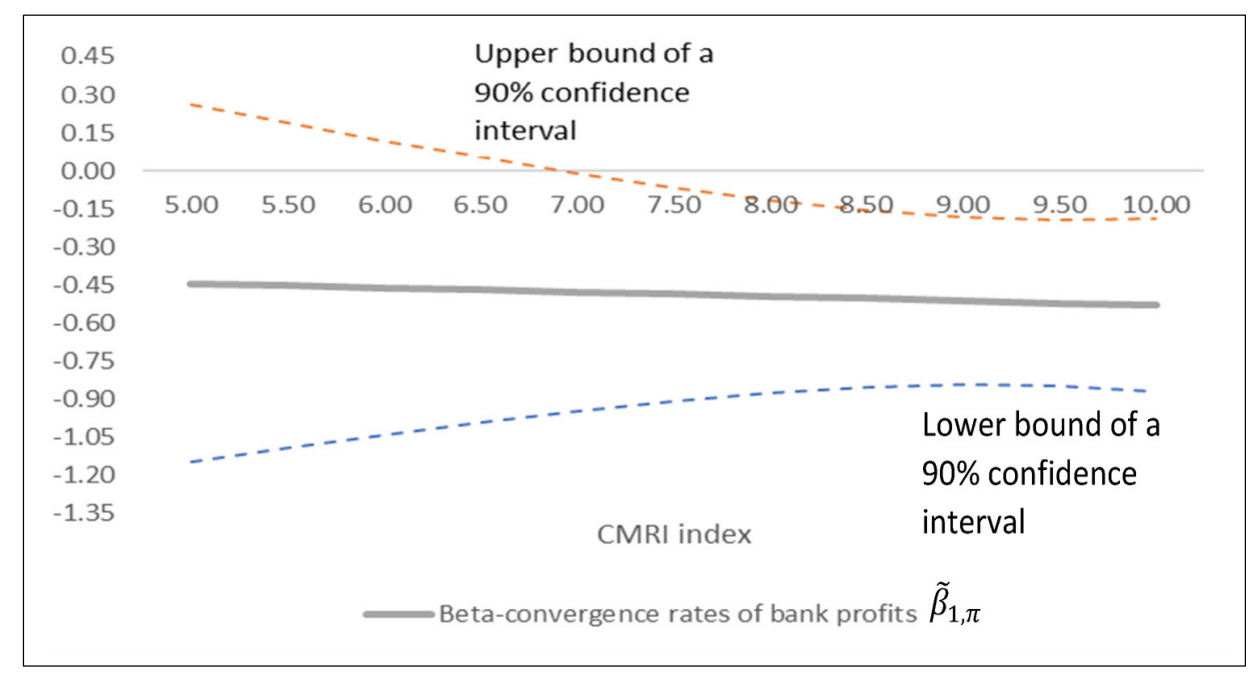

However, the threshold applied to the CMRI index is computed on the basis of the assumption that an average score of 7.61 is maintained on the SOG index. A lower average SOG index score needs to be compensated for with a higher CMRI index score if the convergence rate 
is to remain significant. For example, if the average SOG index score declines to 6 , then the minimum CMRI index score is at least 7.5 if the convergence rate is to be significant. This logic is intuitive because both freedom indexes are uncovered to positively determine the beta-convergence rate of bank profits.

Figure 2. Beta-convergence rates as determined by the SOG index when holding the CMRI index constant at 8.83 . Estimated parameters of model $2.1 \mathrm{~b}$ are used to plot the beta-convergence rates.

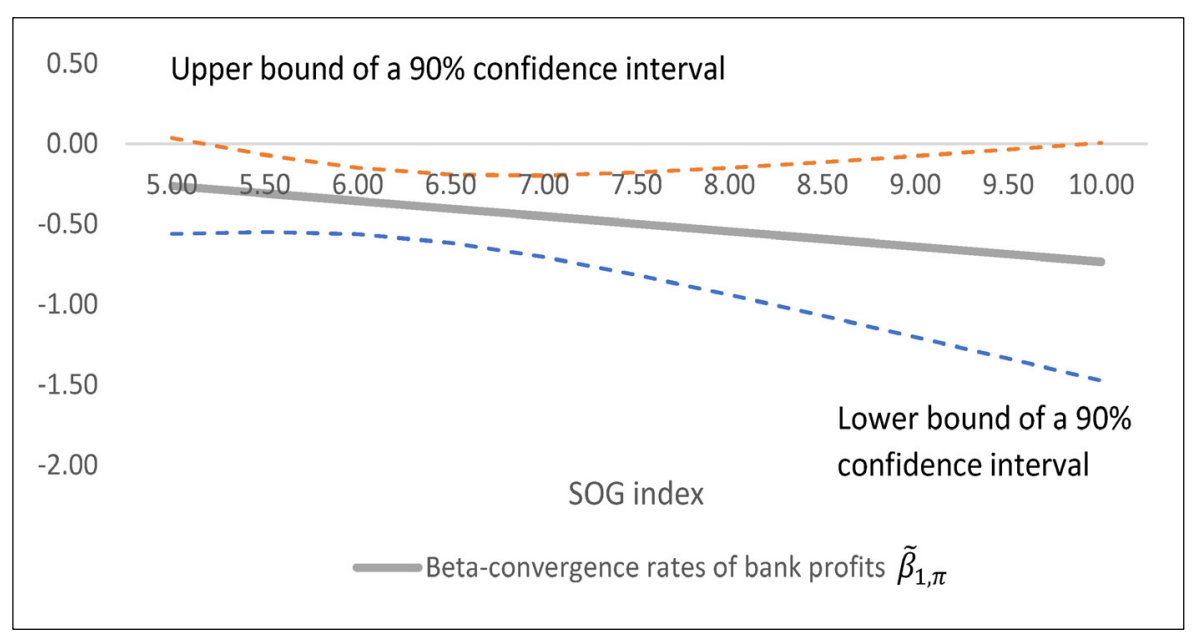

In turn, Figure 2 plots the beta-convergence rates that are determined by a range of SOG scores when holding the CMRI index constant at its mean. Figure 2 shows that the minimum SOG score for the beta-convergence rate of bank profits to turn significant is at approximately 5.3 , ceteris paribus, which is much lower than that is required for the CMRI index (Figure 1). Similar too credit market freedom, a smaller government is found to have no significant marginal effects on bank profits' beta-convergence rate. Yet, a conditional relationship between the SOG and bank profits' convergence still prevails. Notably, ASEAN-5 members are still required to curb their fiscal spending and maintain their government size at smaller than a certain level to yield the minimum SOG score if bank profits are to converge significantly.

Although the average SOG score of 7.61 is highly unlikely to decline significantly to the threshold of 5.3, Figure 3 shows that the current trend is worrisome. Other than Malaysia, over the years, other ASEAN-5 members' government expenditures on final consumption (as a percent of GDP) are viewed as either increasing or remaining unchanged. An increasing trend is rather apparent for countries such as the Philippines and Singapore. 
Figure 3. Government expenditure on final consumption as percent of GDP for ASEAN-5 members.

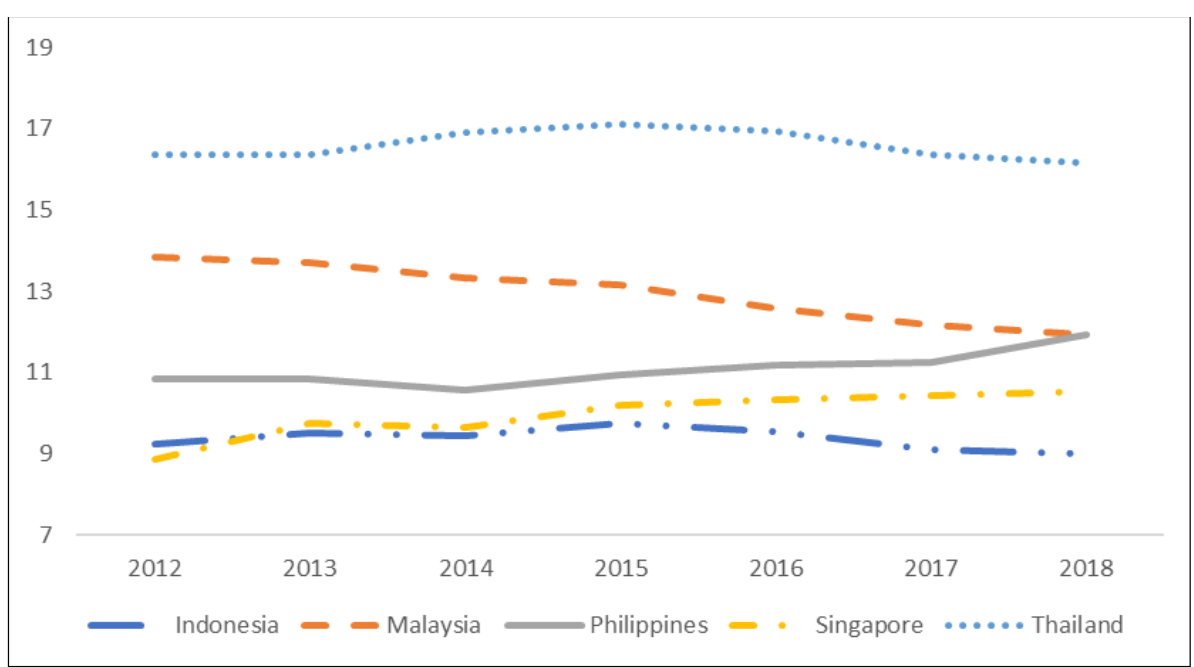

(Source) World Bank database

Given that economic growth is impeded when fiscal spending contracts, the temptation is strong for governments to spend incessantly because economic growth is connected to the ruling party's electoral success. Therefore, observing a small government size proves to be a more difficult challenge requiring not only more grit than that is required for liberalizing the banking sector but also substantial integrity from the ruling party. Nonetheless, Kim (2011), Jones and Smith (2007), and Jones (2016) highlighted that these resolutions and integrity are lacking.

Thus, despite the significant buffer between the prevailing average SOG score and the minimum threshold, if a proper system of governance is not implemented to prevent governments from abusing their power, then ASEAN members are likely to decline to beyond the minimum threshold on the SOG index. The resultant implication is non-converging bank profits, as predicted by the empirical evidence from this study, which subsequently thwarts any effort spent to integrate the ASEAN-5 banking sectors. Moreover, other countries that have scored lower than the threshold of 5.3 as of 2015 are just as entrenched in state sovereignty as some of the ASEAN members, such as China, Argentina, and Brazil.

\section{B. Robustness check: convergence of the ROAA}

The results yielded from Table 2 are ensured to be robust by estimating Eq (1) for the second time to examine the beta-convergence of banks' ROAA instead of profits. Estimates of the ROAA convergence model, which are presented in Appendix $\mathrm{C}$, are found to be consistent with the results presented in Table 2. Indeed, similar to the beta-convergence of bank profits, the marginal effects of economic freedom variables on the beta-convergence of the ROAA 
are found to be insignificant. However, Figure 4 and Figure 5, which plot the beta-convergence rates of the ROAA over a range of CMRI and SOG scores, respectively, show that these beta-convergence rates - as determined by these respective indexes-only turn significant beyond a certain minimum score while holding another index constant at its mean. Thus, not unlike bank profits, these economic freedom variables are found to have certain threshold effects on ROAA convergence.

Figure 4. Beta-convergence rates of bank ROAAs as determined by the CMRI index when holding the SOG index constant at 7.61. Estimated parameters of model B in Appendix C are used to plot the beta-convergence rates.

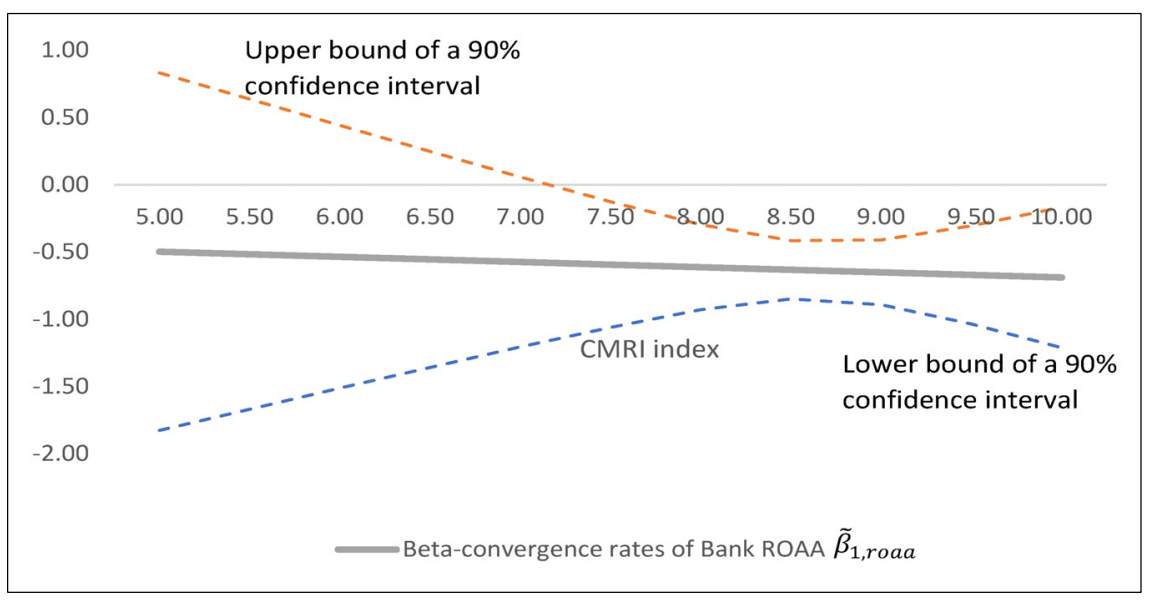

Figure 5. Beta-convergence rates of the ROAA as determined by the SOG index when holding the CMRI index constant at 8.83. Estimated parameters of model B in Appendix $\mathrm{C}$ are used to plot the beta-convergence rates.

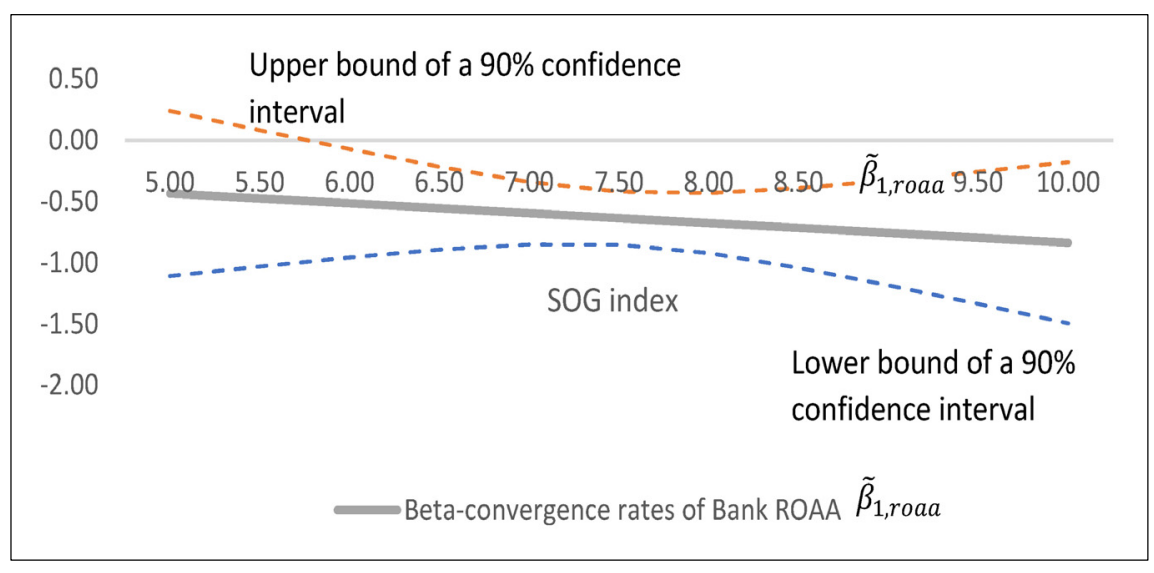

Because ROAA convergence requires free mobility of bank assets to equalize the returns through arbitrage, the uncovered thresholds on the CMRI and SOG indexes suggest that if 
these indexes score lower than a certain level, then bank assets' mobility will be so significantly impeded that the ROAA will be hindered from converging.

\section{Conclusions and Implications on Policymaking}

With respect to the agenda to foster a deeper integration among the ASEAN banking sectors, one of the approaches to measure the depth of the integration is bank profitability convergence. Thus, this study examines how different sources of economic freedom determine the betaconvergence of the two proxies of bank profitability - bank profits and ROAA. In this study, two sources of economic freedoms - credit market freedom as measured by the CMRI index and the size of government, measured by the SOG index-are jointly considered.

Although none of the economic freedom variables are found to have any significant marginal effects on the beta-convergence of bank profitability, Brambor et al. (2005) maintained that this finding does not necessarily invalidate the hypothesized conditional relationship between the two. Indeed, the beta-convergence rates of bank profitability are only found to turn significant beyond a certain minimum score on the respective freedom index.

Although increased credit market freedom and reduced government size are not found to bear any significant impact on the beta-convergence of bank profitability, according to a minimum level of freedom to the credit market and preventing the government from growing beyond a decent size are still necessary for significant bank profitability convergence. The potential risk is in maintaining a decent government size because the temptation to use fiscal spending to engineer economic growth is significant when the ruling party's electoral success depends on the economy during its governance.

As it is, the trend of increasing government expenditures on final consumption (as a percent of GDP) is apparent for Singapore and the Philippines (as shown in Figure 3). Thus, a wise move is for the ASEAN secretariat to put forth mechanisms to monitor the extent of government spending in the respective member states because the risk of non-converging bank performance is amplified when a fiscal tool is used incessantly in domestic economies.

\section{References}

Agostino, M., Leonida, L., \& Trivieri, F. (2005). Profits persistence and ownership: evidence from the Italian banking sector. Applied Economics, 37, 1615-1621.

Aiken, L. S., \& West, S. G. (1991). Multiple regression: Testing and interpreting interactions. Newbury Park, CA: Sage. 
Akhigbe, A., \& McNulty, J. (2005). Profit efficiency sources and differences among small and large US commercial banks. Journal of Economics and Finance, 29, 289-299.

Amidu, M., \& Harvey, S. K. (2016). The persistence of profits of banks in Africa. Review of Quantitative Finance and Accounting, 47, 83-108.

Arellano, M., \& Bond, S. (1991). Some tests of specification for panel data: Monte Carlo evidence and an application to employment equations. The review of economic studies, 58, 277-297.

Arellano, M., \& Bover, O. (1995). Another look at the instrumental variable estimation of error-components models. Journal of econometrics, 68, 29-51.

Athanasoglou, P. P., Brissimis, S. N., \& Delis, M. D. (2008). Bank-specific, industry-specific and macroeconomic determinants of bank profitability. Journal of international financial Markets, Institutions and Money, $18,121-136$.

Barro, R. J., \& Sala-i-Martin, X. (1992). Convergence. Journal of political Economy, 100, 223-251.

Barro, R. J., Sala-i-Martin, X., Blanchard, O. J., \& Hall, R. E. (1991). Convergence across states and regions. Brookings papers on economic activity, 1, 107-182.

Bektas, E. (2007). The persistence of profits in the Turkish banking system. Applied Economics Letters, 14, 187-190.

Brambor, T., Clark, W. R., \& Golder, M. (2006). Understanding interaction models: Improving empirical analyses. Political analysis, 14, 63-82.

Burbidge, J. B., Magee, L., \& Robb, A. L. (1988). Alternative transformations to handle extreme values of the dependent variable. Journal of the American Statistical Association, 83, 123-127.

Calderon, C. A., Chong, A., \& Loayza, N. V. (2002). Determinants of current account deficits in developing countries. The BE Journal of Macroeconomics, 2(1).

Chronopoulos, D. K., Liu, H., McMillan, F. J., \& Wilson, J. O. (2015). The dynamics of US bank profitability. The European Journal of Finance, 21, 426-443.

Demsetz, H. (1973). Industry structure, market rivalry, and public policy. The Journal of Law and Economics, 16, $1-9$.

Evans, P., Hasan, I., \& Lozano-Vivas, A. (2008). Deregulation and convergence of banking: The EU experience. Finnish Economic Papers, 21, 104-117.

Friedrich, R. J. (1982). In defense of multiplicative terms in multiple regression equations. American Journal of Political Science, 797-833.

García-Herrero, A., Gavilá, S., \& Santabárbara, D. (2009). What explains the low profitability of Chinese banks? Journal of Banking \& Finance, 33, 2080-2092.

Garza-García, J. G. (2012). Does market power influence bank profits in Mexico? A study on market power and efficiency. Applied Financial Economics, 22, 21-32.

Goddard, J., Liu, H., Molyneux, P., \& Wilson, J. O. (2011). The persistence of bank profit. Journal of Banking \& Finance, 35, 2881-2890.

Goddard, J., Liu, H., Molyneux, P., \& Wilson, J. O. (2013). Do bank profits converge? European Financial Management, 19, 345.

Gugler, K., \& Peev, E. (2018). The persistence of profits in banking: an international comparison. Applied Economics, 50, 1-14. 
Hair, J. F. Jr., Anderson, R. E., Tatham, R. L., \& Black, W. C. (1995). Multivariate Data Analysis (3rd ed.). New York: Macmillan.

Hayakawa, K. (2009). First difference or forward orthogonal deviation-Which transformation should be used in dynamic panel data models?: A simulation study. Economics Bulletin, 29(3), 2008-2017.

Im, K. S., Pesaran, M. H., \& Shin, Y. (2003). Testing for unit roots in heterogeneous panels. Journal of Econometrics, 115, 53-74.

Johnson, N. L. (1949). Systems of Frequency Curves Generated by Methods of Translation. Biometrika, $36,149-76$.

Jones, L. (2016). Explaining the failure of the ASEAN economic community: The primacy of domestic political economy. The Pacific Review, 29, 647-670.

Jones, D. M., \& Smith, M. L. (2007). Making process, not progress: ASEAN and the evolving East Asian regional order. International Security, 32, 148-184.

Kennedy, P. (2008). A guide to econometrics. Malden, MA: Blackwell Publishing.

Kim, M. H. (2011). Theorizing ASEAN integration. Asian Perspective, 35, 407-435.

Liu, L., Liu, Q., Tian, G., \& Wang, P. (2018). Government connections and the persistence of profitability: Evidence from Chinese listed firms. Emerging Markets Review, 36, 110-129.

Mueller, D. C. (1977). The persistence of profits above the norm. Economica, 44, 369-380.

Mueller, D. C. (1983). The determinants of persistent profits. Washington, DC: Bureau of Economics, Federal Trade Commission.

Olson, D., \& Zoubi, T. (2017). Convergence in bank performance for commercial and Islamic banks during and after the Global Financial Crisis. The Quarterly Review of Economics and Finance, 65, 71-87.

Pervan, M., Pelivan, I., \& Arnerić, J. (2015). Profit persistence and determinants of bank profitability in Croatia. Economic research-Ekonomska istraživanja, 28, 284-298.

Phillips, P., \& Sul, D. (2007). Transition modelling and econometric convergence tests. Econometrica, 75, 1771-1855.

Roodman, D. M. (2009). How to do xtabond2: An introduction to Difference and System GMM in Stata. The Stata Journal, 9, 86-136.

Sala-i-Martin, X. X. (1996). The classical approach to convergence analysis. The Economic Journal, 106, 1019-1036.

Sala-i-Martin, X. (2002). 15 years of new growth economics: What have we learnt? (UPF Economics and Business Working Paper No. 620).

Sinha, P., \& Sharma, S. (2016). Determinants of bank profits and its persistence in Indian Banks: A study in a dynamic panel data framework. International Journal of System Assurance Engineering and Management, 7, 35-46.

Windmeijer, F. (2005). A finite sample correction for the variance of linear efficient two-step GMM estimators. Journal of econometrics, 126, 25-51. 

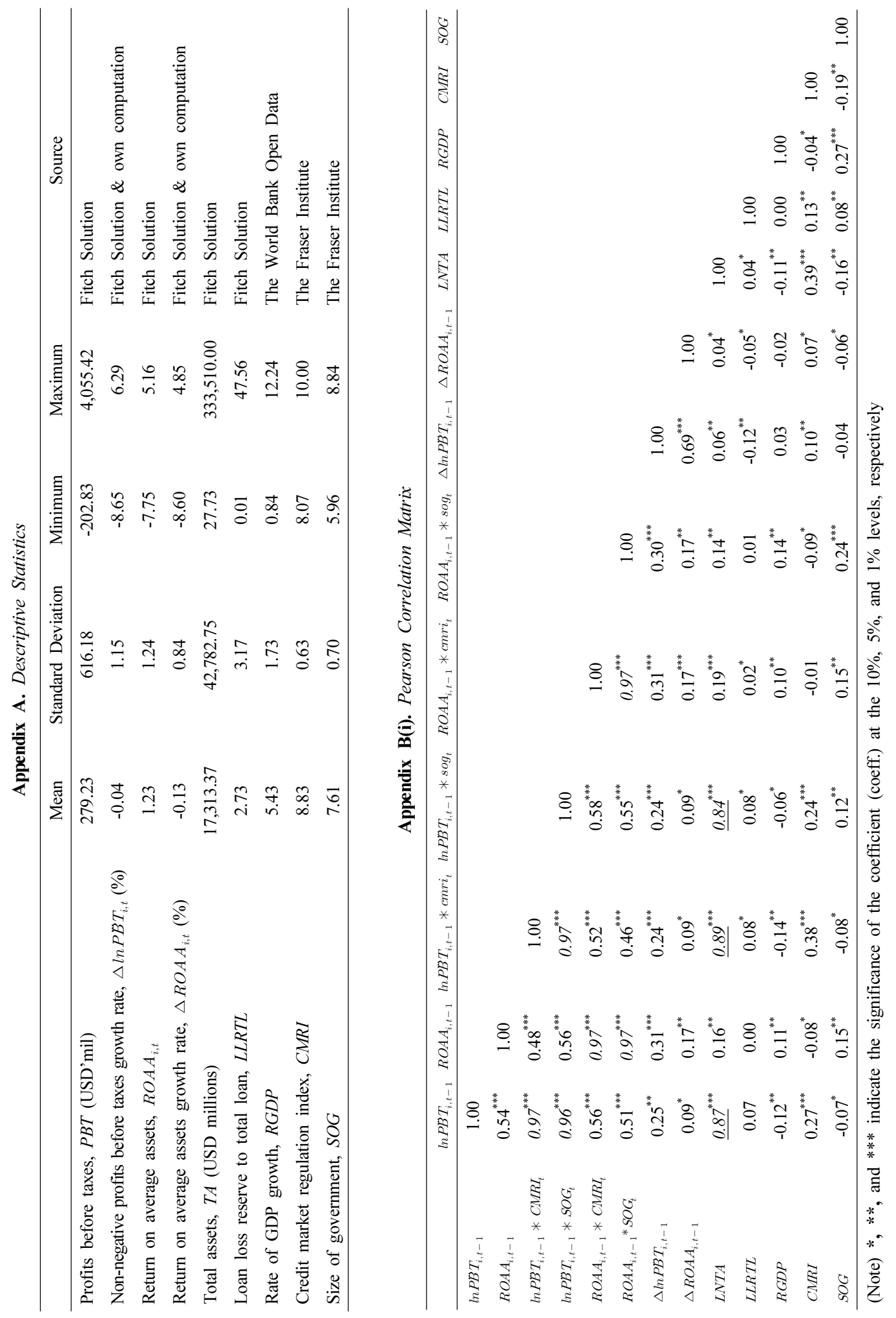
Appendix B(ii). VIF for LNTA vs. Terms with Lagged Non-Negative Profits Before Taxes

\begin{tabular}{llll}
\hline & M1 & M2 & M3 \\
\hline LNTA & 5.48 & 5.85 & 5.20 \\
$\ln P B T_{i, t-1}$ & 5.32 & & \\
$\ln P B T_{i, t-1} * C M R I_{t}$ & & 5.72 & 5.37 \\
$\ln P B T_{i, t-1} * S O G_{t}$ & & & \\
\hline
\end{tabular}


Appendix C. Results for the Robust Estimation of ROAA Beta-Convergence Conditioned by CMRI and SOG

\begin{tabular}{|c|c|c|c|c|}
\hline & \multicolumn{4}{|c|}{ Convergence of ROAA } \\
\hline & \multicolumn{2}{|c|}{$\begin{array}{l}\text { Model A: } \\
\text { First differencing }\end{array}$} & \multicolumn{2}{|c|}{$\begin{array}{l}\text { Model B: Forward } \\
\text { orthogonality }\end{array}$} \\
\hline & Coef. & $\begin{array}{l}\text { C. Std. } \\
\text { Err. }\end{array}$ & Coef. & $\begin{array}{l}\text { C. Std. } \\
\text { Err. }\end{array}$ \\
\hline \multicolumn{5}{|l|}{ Dependent Variable: Return on Average Asset growth $\left(\triangle R O A A_{i, t-1}\right)$} \\
\hline Lagged Return on Average Assets $\left(R O A A_{i, t-1}\right), \beta_{1, \pi}$ & 0.31 & 1.57 & 0.59 & 1.79 \\
\hline $\begin{array}{l}\text { Lagged Return on Average Assets * Credit market regulation index } \\
\left(R O A A_{i, t-1} * C M R I\right), \beta_{2, \pi, \tau=1}\end{array}$ & -0.04 & 0.22 & -0.03 & 0.25 \\
\hline $\begin{array}{l}\text { Lagged Return on Average Assets * Size of government } \\
\left(R O A A_{i, t-1} * S O G\right), \beta_{2, \pi, \tau=2}\end{array}$ & -0.08 & 0.15 & -0.07 & 0.15 \\
\hline Credit Market Regulation Index * Size of government $(C M R I * S O G), \beta_{3, \pi}$ & -0.25 & 0.35 & -0.04 & 0.39 \\
\hline Lagged difference Return on Average Assets $\left(\ln \triangle R O A A_{i, t-1}\right), \beta_{4, \pi}$ & -0.01 & 0.06 & 0.00 & 0.06 \\
\hline \multicolumn{5}{|l|}{ Control variables } \\
\hline Total assets in logarithm $(L N T A), \delta_{1, \pi}$ & -0.08 & 0.10 & -0.16 & 0.12 \\
\hline Loan loss reserve to total loans $(L L R T L), \delta_{2, \pi}$ & 0.04 & 0.07 & 0.10 & 0.08 \\
\hline GDP growth rate $(R G D P), \delta_{3, \pi}$ & $-0.05^{* *}$ & 0.02 & $-0.05^{* *}$ & 0.02 \\
\hline Credit market regulation index, $\beta_{5, \pi, \tau=1}$ & 2.09 & 2.48 & 0.60 & 2.77 \\
\hline Size of government, $\beta_{5, \pi, \tau=2}$ & 2.38 & 3.30 & 0.41 & 3.80 \\
\hline \multicolumn{5}{|l|}{ Year effects } \\
\hline 2012 & $0.39^{* * *}$ & 0.08 & $0.41^{* * *}$ & 0.09 \\
\hline 2013 & $0.24^{* * *}$ & 0.08 & $0.26^{* * *}$ & 0.10 \\
\hline cons, $\alpha_{1}$ & -18.80 & 24.14 & -20.68 & 27.74 \\
\hline No of Observations & \multicolumn{2}{|c|}{492} & \multicolumn{2}{|c|}{492} \\
\hline No of Groups & \multicolumn{2}{|c|}{133} & \multicolumn{2}{|c|}{133} \\
\hline No of Instruments & \multicolumn{2}{|c|}{49} & \multicolumn{2}{|c|}{49} \\
\hline $\mathrm{AB}(1) \mathrm{p}$-value & \multicolumn{2}{|c|}{0.112} & \multicolumn{2}{|c|}{0.115} \\
\hline $\mathrm{AB}(2) \mathrm{p}$-value & \multicolumn{2}{|c|}{0.282} & \multicolumn{2}{|c|}{0.260} \\
\hline (i) Hansen $J$ test p-value & \multicolumn{2}{|c|}{0.406} & \multicolumn{2}{|c|}{0.439} \\
\hline \multicolumn{5}{|l|}{ Difference in Hansen test (p-value) } \\
\hline \multicolumn{5}{|l|}{ GMM instruments for level: } \\
\hline Excluding group & \multicolumn{2}{|c|}{0.315} & \multicolumn{2}{|c|}{0.378} \\
\hline (ii) Lagged first-difference instruments & \multicolumn{2}{|c|}{0.583} & \multicolumn{2}{|c|}{0.528} \\
\hline
\end{tabular}

(Notes) These results are estimated using the two-step system GMM estimator. The corrected standard error (C. Std Err.) presented is as per Windmeijer (2005). Year effects are dutifully examined for each model, and only significant effects for any particular year are accounted for in the model. *,**, and *** indicate the significance of the coefficient (coeff.) at the $10 \%, 5 \%$, and $1 \%$ levels, respectively. The coefficient indicators $\pi$ and roaa indicate whether the coefficients are associated with bank profits or the ROAA convergence models. $\mathrm{AB}(1)$ and $\mathrm{AB}(2)$ refer to the Arellano-Bond tests for first- and second-order serial correlations, respectively. (i)-(iii) are the p-values of a series of Hansen $J$ and $C$ tests on instrument validity. (i) refers to the p-value of the overall test on instrument validity. (ii) refers to the p-values of the test on the validity of the level instruments for the first-difference equation. (iii) is the validity test for the first-difference instruments for the level equations. The dimensionality of the instrumental variable matrix is reduced using the approach proposed by Calderon et al. (2002). 